\title{
Yield of colonoscopy with special reference to lower gastrointestinal bleeding in a tertiary referral center in Eastern India
}

\author{
Gautam Ray \\ Department of Medicine, Gastroenterology Unit, B. R. Singh Hospital, Eastern Railway, Kolkata, West Bengal, India
}

\begin{abstract}
\end{abstract}
\section{Introduction}

Colonoscopy is commonly performed nowadays for lower gastrointestinal (GI) symptoms. The indications for which referral to a particular center is done, depends on the

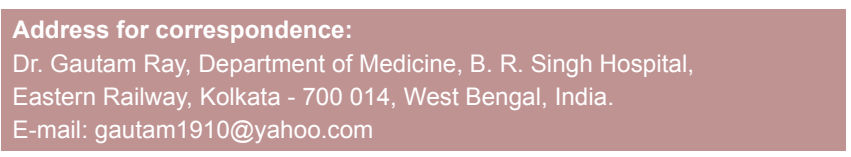

\begin{tabular}{|l|c|}
\hline \multicolumn{2}{|c|}{ Access this article online } \\
\hline \multirow{2}{*}{$\begin{array}{l}\text { Website: } \\
\text { www.jdeonline.in }\end{array}$} & Quick Response Code \\
\hline DOI: & \\
$10.4103 / 0976-5042.165700$ & \\
\hline
\end{tabular}

population which it subserves, the ease of access to it, as also the attitude of referring doctors. However, of the numerous indications, evaluation of lower GI bleed is possibly the most worrisome and common reason. There is a lack of published data from India regarding the value of colonoscopy in its different indications, especially lower GI bleed where the anxiety of cancer and other serious disease is high among patients.

This is an open access article distributed under the terms of the Creative Commons Attribution-NonCommercial-ShareAlike 3.0 License, which allows others to remix, tweak, and build upon the work non-commercially, as long as the author is credited and the new creations are licensed under the identical terms.

For reprints contact: reprints@medknow.com

How to cite this article: Ray G. Yield of colonoscopy with special reference to lower gastrointestinal bleeding in a tertiary referral center in Eastern India. J Dig Endosc 2015;6:110-4. 
Further, no formal guidelines exist in India regarding the sequence of the performance of endoscopy (esophagogastroduodenoscopy [EGD] and/or colonoscopy) in the cases of GI bleed. Western guidelines are formulated based on the prevalence of suspected lesions in their population as well as the cost-effectiveness of endoscopy in the setting. Most studies are in the patients of positive fecal occult blood test (FOBT) with/without iron deficiency anemia (IDA) and guidelines are variable, some advocating colonoscopy first followed by EGD if negative $e^{[1,2]}$ and some advocating bidirectional endoscopy. ${ }^{[3]}$ In both the cases, the write up is driven by the lower detection rate of gastric cancer compared to colon cancer in the West in positive FOBT cases ${ }^{[4]}$ as well as clinically insignificant lesions on EGD which do not need therapeutic intervention. ${ }^{[1,5]}$ The bottom line is the cost benefit ratio inclusive of hospital stay, procedure cost vis-a-vis patient's benefit. In India, the situation is different. The incidence of gastric cancer is higher than colon cancer. Upper and lower GI endoscopies are cheaper (upper $<<$ lower) with increasingly easy availability and performance on an outpatient basis. This along with the fear of missing important lesion makes its performance pressing and so often nonselective and unscrupulous.

The present center caters to a population served largely at the ground level by general doctors who have a low threshold for referral. In addition, it is partly open access where a patient can directly attend for sufficient reason. The study was aimed at (1) finding the yield of colonoscopy in its different indications in such an open access referral system and more importantly (2) finding the detection rate of different lesions by endoscopy in the different types of GI bleed (especially cancers) and also since EGD is cheaper, whether its prior performance can eliminate the need or help to select further colonoscopy.

\section{Methods}

In this retrospective, observational study, all the patients undergoing colonoscopy from January 2007 to December 2013 were included. The predominant clinical symptom which mandated colonoscopy was noted based on which other appropriate tests were done before colonoscopy, e.g. complete hemogram, stool occult blood by Guaiac test, ultrasonography and/or computed tomography scan abdomen, enteroclysis, and EGD. Our policy is to perform EGD, first for all the cases of suspected GI bleed (overt [melena or hematochezia] or occult) with/without IDA and do colonoscopy in those who are negative for any clinically important lesions and where there is a suspicion of colonic pathology on other tests. All EGD and colonoscopies were performed with Pentax FG 29V and FC 38F video endoscope and video colonoscope, respectively, and diagnosis was arrived at by history, appearance of lesion, or biopsy as appropriate. GI bleed was noted as overt (hematochezia or melena) or occult along with associated IDA, if any. The various upper GI lesions diagnosed by EGD in the corresponding years in those having presentation with lower GI bleed and/or IDA were also noted to determine the importance of each as cause and also for comparison with similar presentations of colon cancer and polyps.

\section{Statistical analysis}

Age was represented as mean \pm standard deviation (SD) (range) and compared by Student's $t$-test. Other results were expressed as proportions/percentages. Difference of proportions was compared by the Z-test and a two-sided $P$ value $<0.05$ was considered as significant.

\section{Results}

A total of 826 cases were referred for colonoscopy of which 69 were canceled due to various reasons (low GC, poor bowel preparation, no consent, and inability to tolerate procedure), so 757 cases were included in the final analysis. The various indications for referral along with diagnostic yield per indication are represented in Table 1 and the various diagnoses along with year wise break up are represented in Table 2. Piles was the only diagnosis in $29.6 \%$ cases except which the overall yield was low $(25.7 \%)$. Leaving 30 procedures performed in postoperative cases and 8 cases having miscellaneous diagnosis (rectal prolapse, fistula, anal fissure, and perianal abscess), colonoscopy was normal in 309 (40.82\%) cases. The mean age \pm SD (range) and M: F ratio for overall group, the group with normal colonoscopy, and the group with a diagnosis were $55.41 \pm 15.68$ (12-86); $453: 304$ (1.49:1), $55.32 \pm 14.23(21-86) ; 1.31: 1(175: 134)$, and $55.88 \pm 12.78(12-$ $84) ; 101: 85$ (1.19), respectively ( $P=$ not significant). Similar data for the individual diagnosis are shown in Table 2 . The sex ratio for different age groups is represented in Figure 1. Location of polyps were rectal 13 , sigmoid colon 12 , transverse colon 3 , ascending colon/cecum 5; and those of cancer were rectal 31,

\begin{tabular}{|c|c|c|c|}
\hline Cause for referral & $\begin{array}{l}\text { Number } \\
\text { of cases }\end{array}$ & $\begin{array}{c}\text { Positive } \\
\text { diagnosis } \\
(\%)\end{array}$ & Remarks \\
\hline Pain in left lower abdomen & 65 & $8(12.3)$ & \\
\hline Constipation & 55 & $7(12.7)$ & 8 piles \\
\hline $\begin{array}{l}\text { Suspected intestinal } \\
\text { obstruction }\end{array}$ & 32 & $8(25)$ & \\
\hline $\begin{array}{l}\text { Asymptomatic } \\
\text { secondaries in liver }\end{array}$ & 36 & $7(19.4)$ & All 7 had cancer \\
\hline Abdominal mass & 18 & 7 (38.9) & $\begin{array}{l}3 \text { cancer, } 4 \text { external } \\
\text { compression }\end{array}$ \\
\hline $\begin{array}{l}\text { Assess postoperative } \\
\text { recurrence of colon cancer }\end{array}$ & 30 & All normal & \\
\hline Elevated CEA & 17 & $6(35.3)$ & All cancer \\
\hline GI bleed & 334 & $151(45.2)$ & Rest 183 piles \\
\hline $\begin{array}{l}\text { Frequent stool/mucus } \\
\text { in stool }\end{array}$ & 138 & All normal & 15 piles \\
\hline $\begin{array}{l}\text { Something coming out } \\
\text { per rectum }\end{array}$ & 32 & $4(12.5)$ & 18 piles \\
\hline Total & 757 & $194(25.6)$ & $\begin{array}{l}\text { Includes } 8 \\
\text { miscellaneous }\end{array}$ \\
\hline
\end{tabular}

CEA=Carcinoembryonic antigen, $\mathrm{Gl}=$ Gastrointestinal, 4 cases of external compression not considered in Positive Diagnosis 


\begin{tabular}{|c|c|c|c|c|c|c|c|c|}
\hline Year & 2007 & 2008 & 2009 & 2010 & 2011 & 2012 & 2013 & Total (\%) \\
\hline Total number of colonoscopies & 145 & 92 & 100 & 110 & 118 & 97 & 95 & 757 \\
\hline SRUS (53.61ะ10.52 [50-67], 3:4) & 2 & 0 & 1 & 2 & 1 & 0 & 1 & $7(0.9)$ \\
\hline Telangiectasia $(60.45 \pm 13.14$ [45-78], 6:3) & 4 & 1 & 0 & 2 & 1 & 1 & 0 & $9(1.2)$ \\
\hline Colonic polyp (56.93 \pm 19.81 [7-80], 20:16) & 8 & 1 & 6 & 6 & 5 & 8 & 2 & $36(4.8)$ \\
\hline Colon cancer (60.92 \pm 13.34 [32-84], 23:27) & 10 & 6 & 8 & 4 & 10 & 6 & 6 & $50(6.6)$ \\
\hline Radiation proctitis $(50.34 \pm 9.74[38-65], 1: 9)$ & 2 & 0 & 1 & 0 & 1 & 3 & 3 & $10(1.3)$ \\
\hline Ulcerative colitis (45.16 \pm 15.14 [23-68], 15:9]) & 5 & 5 & 4 & 3 & 3 & 1 & 3 & $24(3.2)$ \\
\hline Ileitis $(42.49 \pm 14.42$ [23-60], 8:4) & 4 & 2 & 1 & 2 & 3 & 0 & 0 & $12(1.6)$ \\
\hline Colitis $(57.38 \pm 13.88$ [42-74], 12:7) & 3 & 2 & 2 & 5 & 3 & 2 & 2 & $19(2.5)$ \\
\hline Diverticulosis (68.3 \pm 8.24 [60-75], 2:1) & 0 & 1 & 1 & 0 & 1 & 0 & 0 & $3(0.4)$ \\
\hline SI bleed $(53.45 \pm 11.63$ [40-67], 5:2) & 0 & 1 & 1 & 1 & 0 & 2 & 2 & $7(0.9)$ \\
\hline Stricture $(54.21 \pm 8.74$ [42-67], 3:2) & 0 & 1 & 1 & 0 & 1 & 0 & 2 & $5(0.7)$ \\
\hline External compression $(56.36 \pm 12.3$ [44-69], 3:1) & 0 & 1 & 0 & 1 & 0 & 1 & 1 & $4(0.5)$ \\
\hline Miscellaneous (48.14 \pm 11.34 [35-62], 6:2) & 2 & 1 & 1 & 0 & 2 & 1 & 1 & $8(1.1)$ \\
\hline Total diagnosis $(55.88 \pm 12.78[7-84], 107: 87)(\%)$ & $38(26.2)$ & $21(22.8)$ & $26(26)$ & $26(23.6)$ & $29(24.6)$ & $24(24.7)$ & $22(23.2)$ & $194(25.7)$ \\
\hline Only piles (53.92ะ16.36 [21-80] 146:78) (\%) & $40(27.6)$ & 29 (31.5) & $16(16)$ & $36(32.7)$ & $42(35.6)$ & $31(32)$ & $30(31.6)$ & $224(29.6)$ \\
\hline
\end{tabular}

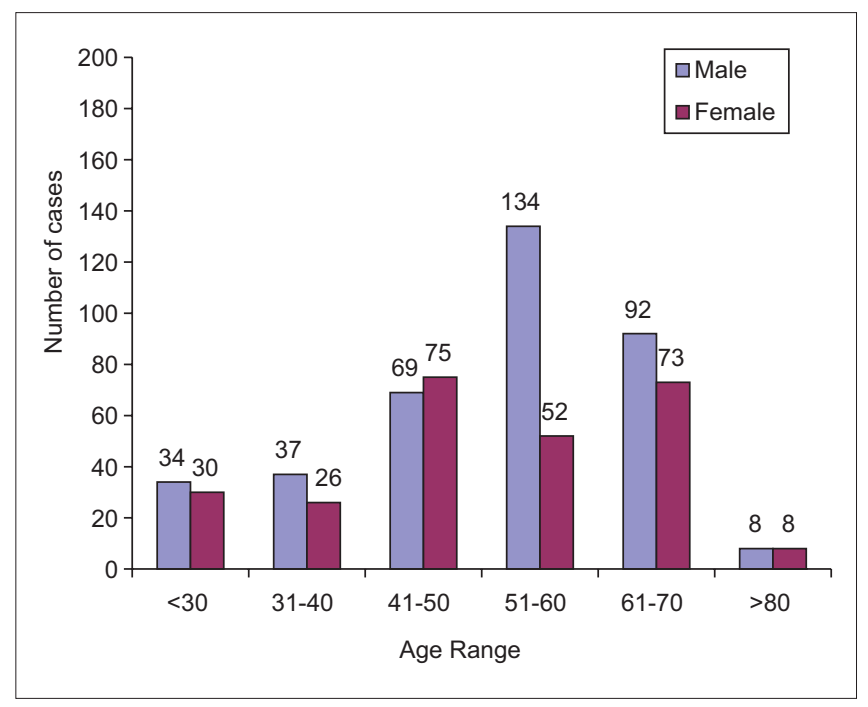

Figure 1: Number of cases of different sex in various age groups

sigmoid colon 13, transverse colon 1, and ascending colon/ cecum 5. Ileitis was due to tuberculosis in 6 cases. Crohn's disease was seen in 3 cases and nonspecific in 3 cases.

The yield in the cases of GI bleed are summarized in Table 3 and the disease wise breakup of presentation as overt or occult bleed with/without IDA is shown in Table 4. Thus, $151 / 334(45.2 \%)$ of all the cases of suspected lower GI bleed had a diagnosis and out of 186 cases with a diagnosis of $151(81.2 \%)$ were presented with lower GI bleed, proving it to be a very important indication for colonoscopy. But at the same time, 183 cases had only piles as etiology of bleed (the rest 41 cases of piles were diagnosed in patients with other symptoms). 45/50 (90\%) cases of colon cancer and $31 / 36(86.1 \%)$ cases of colonic polyps were presented with GI bleed with/without anemia. A positive diagnosis was achieved in $113 / 269(42 \%)$ cases of overt bleed versus $38 / 65(58.5 \%)$ cases of occult bleed $(P=0.02)$. However, in both groups between those having a positive diagnosis with IDA and those without IDA (except piles), presentation with overt bleed was not different from occult bleed ( $P=0.34$ and 0.11 , respectively). IDA was present in $31.1 \%$ cases overall and clinically important lesion was found in $80 / 334$ (24\%) of such cases.

Around 25\% EGD in our unit are performed every year to investigate GI bleed. A total of 1685 EGD were performed in the study period of which a positive diagnosis was arrived at in $37-48 \%(43.2 \%, 727$ cases overall) patients in these years. $86 \%$ of the rest $(826 / 958)$ were considered for colonoscopy of whom $757(79 \%)$ finally underwent the procedure. The overall yield of colonoscopy (leaving piles) was significantly lower $25.7 \%(P=0.000)$ than EGD but with piles it was $55.3 \%$ ( $P$ not significant). The important diagnoses are listed in Table 5 along with their mode of bleeding presentation. Significantly, more number of colonic cancers presenting with hematochezia were detected compared to gastric cancer which presented significantly more often with occult bleed. Other clinical symptoms were present in 65/76 (85.5\%) cases of gastric cancer such as anorexia, weight loss, or abdominal mass whereas it was present in 13/50 (26\%) cases of colon cancer (mass, ascites, and colonic obstruction) and 2/36 (5.6\%) cases of colonic polyp. Asymptomatic hepatic metastasis was present in $15(30 \%)$ colon cancers and only $12 \%$ cases had elevated carcinoembryonic antigen (CEA) level, which accounted for $35.3 \%$ of all cases of elevated CEA (in all such cases the level was more than $10 \mathrm{ng} / \mathrm{ml}$ ).

Except for GI bleed, the yield was modest for other indications and least for nonspecific symptoms of pain abdomen, constipation, frequent stool, or mucus in stool. Incidence of colonic diverticulosis was very low. 


\section{Discussion}

This is possibly the first Indian study of its kind showing the yield of colonoscopy in most of its indications and since it is conducted in an open access system with a predominant general referral base, the results reflect to some extent the attitude of people and doctors to lower GI symptoms and their outcome in this section of population. Lesions similar to our study have been reported from other Asian countries. In a nationwide Chinese survey, involving nearly 54,000 patients, the chief causes of lower GI bleed were similar to our study including the low incidence of diverticulosis. ${ }^{[6]}$ Similar findings were reported from Pakistan and Bangladesh. ${ }^{[7,8]}$ In a nationwide Korean study of 1518 cases of iron deficiency (50\%

\begin{tabular}{lccc}
\hline \multicolumn{4}{c}{ Table 3: Colonoscopic yield in the cases of Gl bleed } \\
$\begin{array}{l}\text { Type of bleed with/ } \\
\text { without anemia }\end{array}$ & $\begin{array}{c}\text { With } \\
\text { a diagnosis (\%) }\end{array}$ & $\begin{array}{c}\text { Only } \\
\text { piles (\%) }\end{array}$ & Total (\%) \\
\hline $\begin{array}{l}\text { Overt }(n=269) \\
\text { With anemia }\end{array}$ & $61(22.7)$ & $7(2.6)$ & $68(20.3)$ \\
$\quad$ No anemia & $52(19.3)$ & $149(55.4)$ & $201(60.2)$ \\
$\begin{array}{l}\text { Occult }(n=65) \\
\text { With anemia }\end{array}$ & $19(29.2)$ & $17(26.2)$ & $36(10.8)$ \\
No anemia & $19(29.2)$ & $10(15.4)$ & $29(8.7)$ \\
Total & $151(45.2)$ & $183(54.8)$ & $334(100)$ \\
\hline Gl=Gastrointestinal & & &
\end{tabular}

\begin{tabular}{lccc}
\hline \multicolumn{4}{l}{ Table 4: Breakup of presentation of Gl bleed disease wise } \\
\hline Diagnosis & Overt (\%) & Occult (\%) & Anemia (\%) \\
\hline SRUS & $7(100)$ & 0 & $2(28.6)$ \\
Telangiectasia & $6(66.7)$ & $3(33.3)$ & $6(66.7)$ \\
Colonic polyp & $21(58.3)$ & $10(27.8)$ & $10(27.8)$ \\
Colonic cancer & $28(56)$ & $17(34)$ & $36(72)$ \\
Radiation proctitis & $10(100)$ & 0 & $5(50)$ \\
Ulcerative colitis & $24(100)$ & 0 & $2(8.3)$ \\
lleitis & $2(16.3)$ & $2(16.3)$ & $4(33.3)$ \\
Colitis & $4(21)$ & $3(15.8)$ & $5(26.3)$ \\
Diverticulosis & 0 & 0 & 0 \\
Small gut bleed & $7(100)$ & 0 & $7(100)$ \\
Stricture & 0 & $3(60)$ & $3(60)$ \\
External compression & 0 & 0 & 0 \\
Miscellaneous & $4(50)$ & 0 & 0 \\
Piles & $156(69.6)$ & $27(10.2)$ & $24(13.1)$ \\
Total & $269(80.5)$ & $65(19.5)$ & $104 / 334(31.1)$ \\
\hline
\end{tabular}

Anemia means $\mathrm{Hb}<10 \mathrm{~g} / \mathrm{dl}$. SRUS=Solitary rectal ulcer syndrome, $\mathrm{SI}=$ Small intestinal, Gl=Gastrointestinal had anemia) by upper and lower GI endoscopy, clinically important lesions were identified in $24.6 \%$ of the patients with anemia with similar frequency of lower GI (13.6\%) and upper GI tract lesions (11.9\%). ${ }^{\left[{ }^{[9]}\right.}$ Even lower yield for isolated abdominal pain has been reported from New Zealand. ${ }^{[10]}$

Our study also showed that the yield of colonoscopy is low for most indications except GI bleed where its yield is high, provided upper GI bleed is excluded by EGD. The type of bleed is important. Large number of overt bleed is caused by piles so it should be excluded by proctoscopy (especially in the cases of its characteristic intermittent, small quantity blood smeared on stool with perianal symptoms) before embarking on colonoscopy. This was due to a low threshold for referral. EGD detected more lesions than subsequent colonoscopy, so it is very useful as an initial investigation for GI bleed and helps to select subsequent colonoscopy judiciously. The yield of colon cancer was low as it is less common in India but more than gastric cancer in the cases of overt bleed. In the cases of occult bleed, yield of gastric cancer was higher. However, previous ongoing occult bleed cannot be excluded in the colon cancer cases. Most cases of gastric cancer had other symptoms, but most colon cancers and polyps were asymptomatic except for the GI bleed. Thus, for overt lower GI bleed (especially melena), colonoscopy should be embarked on after an initial upper GI endoscopy and proctoscopy (for hematochezia) is negative with/without other suggestive symptoms or investigations. A USA study of 1743 colonoscopies performed after a nondiagnostic upper GI endoscopy for melena found positive diagnosis in only $4.2 \% \cdot{ }^{[1]}$ For ongoing hematochezia, colonoscopy is important whatever may be the outcome of EGD.

For occult bleed, colonoscopy is more important after negative upper GI endoscopy, especially if IDA is present. Though only $19.5 \%$ of those with a colonoscopic diagnosis were presented with occult bleed, most of these were the cases of colonic polyps and cancers. British Society of Gastroenterology guidelines for IDA strongly recommends upper and lower GI endoscopies for all such patients, especially those above 50 years age, those with symptoms suggesting GI disease, and those with a strong family history of GI cancer. ${ }^{[12]}$ In an Italian study of patients with IDA, those with positive FOBT had an endoscopic lesion detected in $79.2 \%$ cases, at both upper

\begin{tabular}{|c|c|c|c|c|c|c|}
\hline Diseases & Total (\%) & Overt bleed (\%) & Hematochezia (\%) & Melena (\%) & Occult bleed (\%) & Anemia (\%) \\
\hline Gastric cancer & $76 / 1685$ (4.5) & $3(3.9)$ & 0 & $3(3.9)$ & $47(61.8)$ & $57(75)$ \\
\hline Gastric ulcer & $34 / 1685$ (2) & $9(26.5)$ & $1(3)$ & $8(23.5)$ & $25(73.5)$ & $20(58.8)$ \\
\hline Duodenal ulcer & 111/1685 (6.6) & $101(91)$ & $6(5.4)$ & 95 (85.6) & $10(9)$ & $69(62.2)$ \\
\hline Gastroduodenitis & $308 / 1685(18.2)$ & $268(87)$ & $3(1)$ & $265(86)$ & $40(13)$ & $206(67)$ \\
\hline Esophageal varix & $196 / 1685(11.6)$ & $185(94.4)$ & $3(1.5)$ & $182(92.9)$ & $11(5.6)$ & $156(79.6)$ \\
\hline Colon cancer & $50 / 757(6.6)$ & $28(56)$ & $25(50)$ & $3(6)$ & $17(34)$ & $36(72)$ \\
\hline Colonic polyps & $34 / 757(4.8)$ & $21(58.3)$ & 21 (58.3) & 0 & $10(27.8)$ & $10(27.8)$ \\
\hline
\end{tabular}

$P$ value for the difference of proportions between gastric cancer versus colonic cancer $P=0.03$, occult bleed for gastric versus colonic cancer $P=0.004$, overt bleed for gastric versus colonic cancer $P=0.00001$, anemia for gastric versus colonic cancer $P=0.08$. GI=Gastrointestinal 
endoscopy (52.1\%) and colonoscopy (33.3\%) and FOBT was found to be an independent predictor of both bleeding lesions and cancer. ${ }^{[13]}$ An USA study where $63.4 \%$ subjects were Asians found equal incidence of upper GI and lower GI lesions and of gastric and colonic cancer on bidirectional endoscopy in positive FOBT cases. ${ }^{[14]}$ Gastric cancer was higher among Asians. Similar detection rate of bidirectional endoscopy has been reported from Scandinavia. ${ }^{[15]}$

The main limitations of the study are its retrospective nature with a relatively lesser number of subjects and it has being conducted in one region of the diverse Indian subcontinent. However, we are hopeful that this will provide the platform for future multicentric studies.

\section{Conclusion}

Unselective colonoscopy has low yield for all lower GI symptoms except bleeding in which EGD should possibly be done first to exclude upper GI source of bleed and select subsequent colonoscopy. For ongoing hematochezia and occult bleed, colonoscopy is important whether IDA is present or not. The yield of colon cancer is more than gastric cancer in the cases of overt bleed and less for occult bleed. Serum CEA level has low accuracy for the diagnosis of colonic cancer.

\section{Financial support and sponsorship}

Nil.

\section{Conflicts of interest}

There are no conflicts of interest.

\section{References}

1. Hisamuddin K, Mowat NA, Phull PS. Endoscopic findings in the upper gastrointestinal tract of faecal occult blood-positive, colonoscopy-negative patients. Dig Liver Dis 2006;38:503-7.
2. Ali M, Yaqub M, Haider Z, Anees I, Bhargava S, Gian J. Yield of dual endoscopy for positive fecal occult blood test. Am J Gastroenterol 2003;98:82-5.

3. Velez JP, Schwesinger WH, Stauffer J, Gaskill HV rd, Kazantsev GB, Sirinek KR, et al. Bidirectional endoscopy in patients with fecal occult blood. Surg Endosc 2002;16:117-20.

4. Zappa M, Visioli CB, Ciatto S, Grazzini G, Rubeca T, Bonanomi AG, et al. Gastric cancer after positive screening faecal occult blood testing and negative assessment. Dig Liver Dis 2007;39:321-6.

5. Chen YK, Gladden DR, Kestenbaum DJ, Collen MJ. Is there a role for upper gastrointestinal endoscopy in the evaluation of patients with occult blood-positive stool and negative colonoscopy? Am J Gastroenterol 1993;88:2026-9.

6. Bai Y, Peng J, Gao J, Zou DW, Li ZS. Epidemiology of lower gastrointestinal bleeding in China: Single-center series and systematic analysis of Chinese literature with 53,951 patients. J Gastroenterol Hepatol 2011;26:678-82.

7. Zia N, Hussain T, Salamat A, Mirza S, Hassan F, Waqar A. Diagnostic evaluation of patients presenting with bleeding per rectum by colonoscopy. J Ayub Med Coll Abbottabad 2008;20:73-6.

8. Mollick SH, Roy PK, Bhuiyan MR, Mia AR, Alam MS, Mollick KA, et al. Prevalence of colorectal diseases in immunological fecal occult blood test (I-FOBT) positive patients in a tertiary care hospital in Bangladesh. Mymensingh Med J 2014;23:764-9.

9. Park JS, Park DI, Park SK, Choi JS, Kim YH, Chang DK, et al. Endoscopic evaluation of significant gastrointestinal lesions in patients with iron deficiency with and without anaemia: A Korean Association for the Study of Intestinal Disease study. Intern Med J 2009;39:441-6.

10. Kueh SH, Zhou L, Walmsley RS. The diagnostic yield of colonoscopy in patients with isolated abdominal pain. N Z Med J 2013;126:36-44.

11. Etzel JP, Williams JL, Jiang Z, Lieberman DA, Knigge K, Faigel DO. Diagnostic yield of colonoscopy to evaluate melena after a nondiagnostic EGD. Gastrointest Endosc 2012;75:819-26.

12. Goddard AF, James MW, McIntyre AS, Scott BB; British Society of Gastroenterology. Guidelines for the management of iron deficiency anaemia. Gut 2011;60:1309-16.

13. Cilona A,Zullo A, Hassan C, Ridola L, Annese M. Isfaecal-immunochemical test useful in patients with iron deficiency anaemia and without overt bleeding? Dig Liver Dis 2011;43:1022-4.

14. Day LW, Cello JP, Somsouk M, Inadomi JM. Prevalence of gastric cancer versus colorectal cancer in Asians with a positive fecal occult blood test. Indian J Gastroenterol 2011;30:209-16.

15. Stray N, Weberg R. A prospective study of same day bi-directional endoscopy in the evaluation of patients with occult gastrointestinal bleeding. Scand J Gastroenterol 2006;41:844-50. 